\title{
Wastewater systems in the time of Covid-19: surveillance, epidemiology and design
}

\author{
Michael Gormley CEng PhD
}

Director of the Institute for Sustainable Building Design,

Heriot-Watt University, Edinburgh, UK

\section{Introduction}

In the 10 months since the novel coronavirus, SARS-CoV-2, emerged from Wuhan in China, it has spread around the world causing the disease Covid-19, which has, according to official tallies, led to 44 million confirmed cases and has claimed over a million lives. The World Health Organisation (WHO) has recently estimated that these figures are underestimated and that closer to 800 million people have been infected, with a subsequent much higher death toll. In addition to these stark statistics, the virus has caused national governments to limit social and economic interactions leading to hardship. As governments, public health officials, employers and individuals learn to live with the virus until such time that a vaccine or improved treatments can be found, every profession is in the process of adapting and attempting to apply its own principles to mitigating the effects of the virus, and civil engineering is no exception. Enhanced efforts to track the virus through wastewater systems and highlight how wastewater analysis may be of benefit in epidemiological mapping studies. The use of these methods is not without complication and the challenge extends beyond SARS-CoV-2 to any infectious agent detectable in faecal waste and wastewater. The process of potential transmission from the source (typically people in buildings) through to the wastewater treatment plant (WWTP) is explored below.

From early on in the pandemic, studies of infected patients had shown that SARS-CoV-2 ribonucleic acid (RNA) can be detected in the faeces of patients for weeks after the onset of clinical symptoms of the disease (Ding and Liang, 2020). The prevalence of asymptomatic cases poses considerable public health concerns since these people will carry and spread the virus without getting Covid-19. It has been considered plausible that $80 \%$ of the transmitted virus results from $20 \%$ of infected people and that approximately $70 \%$ of infected people transmit the virus to the remaining $20 \%$ of cases, with $10 \%$ not involved in transmission at all. There is thus a contention that this $20 \%$ are 'super-spreaders' - the cause of which is yet to be determined. It is important to remember that both symptomatic and asymptomatic people will shed the virus; however, this is difficult to track since people do not engage clinically when they have no symptoms. As we have observed recently, since there are significant logistical limitations on testing entire communities individually, sampling wastewater for SARSCoV-2 may offer opportunities to map the spread of the disease in the community before an outbreak presents itself in clinical settings.

\section{Transmission and infection}

Transmission of the virus depends on an infected person shedding the viable virus, which is then picked up by a susceptible person. The main methods of transmission include close-range direct person-to-person transmission, which happens when someone is directly exposed to the respiratory droplets emitted by another person. Close-range transmission can also be through direct physical contact with the infectious person. In addition to direct transmission, indirect surface contact transmission is also a risk. This occurs when someone touches a surface that has been contaminated with the virus. They may then become infected when they touch their nose, eyes or mouth with a contaminated hand or object (fomite). A potential faecal/oral/ocular transmission route would involve a person touching their mouth, nose of eyes with hands contaminated with infective faeces or urine.

Infection requires inoculation by sufficient number of viral particles to cause infection - the number of particles required to cause infection is not yet known. However, the infectious dose received depends on the concentration of infectious viral particles multiplied by the duration of exposure, and hence both must be considered when evaluating risk. Best estimates at the moment, based on animal studies, suggest that the infective dose is in the region of $10^{2}-10^{4}$ plaque forming units (DHS, 2020). Putting this in context, wastewater sampling has returned results for virus genetic material in both urine (c. $10^{2}-10^{5} \mathrm{gc} / \mathrm{ml}$ ) and faeces $\left(c .10^{2}-10^{7} \mathrm{gc} / \mathrm{ml}\right)$, which are much lower than in nasopharyngeal fluids $\left(c .10^{5}-10^{11} \mathrm{gc} / \mathrm{ml}\right)$ (Jones et al., 2020).

To date, the faecal-oral/ocular transmission route has not been proven. Early results from work by a small number of researchers, which suggested that virus shed in faeces was infectious, have not been shown to be easily replicated. The process of proving infectivity is more difficult than detecting 
the presence of virus using quantitative polymerase chain reaction (qPCR) techniques, which are widely available. Any positive results for infectivity have been the result of tests on infected patients; no investigation has, to date, found infective virus in wastewater systems.

\section{Wastewater systems}

Finding viral RNA is a relatively easy matter; however, determining the potential number of infectious people in a population presents some major challenges. For example, little or no data exists on SARS-CoV-2 recovery efficiency from samples; normalisation and standardisation of sampling methodology has not been perfected; some researchers are currently using heat-inactivated SARS-CoV-2 and porcine reproductive and respiratory syndrome (PRRS), a surrogate pig virus; recovery rates are very variable (1-50\%). While recovery is consistent across a wide range of concentrations, it can vary dramatically across samples suggesting that stronger process controls are required. These challenges are being met with ongoing research but mostly refer to tightening controls on RNA sampling by qPCR. The question of infectivity of wastewater is still largely unanswered (Corbishley et al., 2020). The technique also suffers from low resolution since sampling is done at the WWTP influent catchment level. Efforts to apply this technique to a building level are problematic as there is little aggregation of waste material since it is still considered discrete (Gormley and Campbell, 2006).

Risk of transmission depends on a number of factors. The highest risk for close-range transmission is when someone is face-to-face with an infectious person at a distance of $2 \mathrm{~m}$ or less for a prolonged period. Aerosol transmission risk is considered to be very low outdoors due to high dilution of virus-carrying aerosols and ultraviolet inactivation of the virus. Aerosol and droplet transmission were considered a potential risk for WWTP operatives at the beginning of the pandemic, as processes within the plant are known to generate aerosols. Anecdotal evidence has suggested that there is not a higher incidence of infection amongst WWTP operatives than those in the community at large.

An aspect of wastewater management that is often overlooked is wastewater systems inside buildings. Mostly considered to be a different field of study and designed by specialists in 'aboveground drainage' the area plays a significant role in the origin and fate of SARS-CoV-2 within wastewater systems since it is inevitably the source. The identification of the wastewater plumbing system (above-ground drainage system) as a potential transmission pathway for pathogens goes back to the SARS outbreak of 2002-2003 and one building that raised concerns at the time. In 2003, WHO published a final report into a superspreading event of SARS within a housing block in Hong Kong. The 41-storey building had over 300 confirmed cases of SARS and 42 deaths (WHO, 2003). The report identified defects in the wastewater plumbing system as a transmission mode within the building, which facilitated the transport of 'virus-laden droplets' through empty U-bends in bathrooms. This airborne transmission route was aided by bathroom extract ventilation, which drew contaminated air into the room. Since then, research on investigating mechanisms of cross-transmission, improving system design and innovative system monitoring, including confirmation of the wastewater plumbing system as a reservoir for pathogens (Gormley et al., 2012, 2014, 2017) has taken place. This should have driven change in the building maintenance and wastewater plumbing sector; however, the sector is slow to change and little happened once SARS had disappeared. Similar concerns are being raised at the moment with evidence emerging that epidemiological studies of outbreaks in high-rise buildings in China and Hong Kong have yet again identified the above-ground drainage system as a probable cause of transmission (Kang, 2020). It is tempting to associate these issues with a particular geographical area of the world; however, there is little difference in design methodologies in every jurisdiction - some variations on approaches exist but fundamentally they are the same. It often comes as surprise to hear that there is no specific design guide for high-rise building drainage and that the same principles that are applied to a low-rise of, say, 4-storey height are applied to buildings of 100-storey height. Another reason for not discounting these examples is that, following SARS-CoV-1 and Middle East respiratory syndrome (MERS), which highlighted such concerns, epidemiologists and public health officials are actively investigating these transmission routes when an outbreak occurs, this is generally not occurring in other geographical areas.

\section{Conclusions}

In conclusion, SARS-CoV-2 has proven to be a resilient and efficient virus for which we have yet to produce a vaccine or effective treatment for the disease it causes - Covid-19. Methods of detecting the virus have focussed on the logistical challenges of testing individuals in conjunction with tracing close contacts. This process only works when the number of infected people is low. Identifying areas of concern before clinical presentation offers the opportunity for public health officials to get ahead of the virus and identify virus 'hot spots' by monitoring the levels of virus in wastewater systems. However, this presents its own challenges in terms of generating protocols and standardisations in order to quantify infection rates in a population.

Wastewater in buildings presents another area of concern. The interface between building wastewater systems (above-ground) and the main sewer network (below-ground) is relatively neglected. Concerns raised by severe acute respiratory syndrome (SARS) in the early 2000s about building wastewater system defects as a probable transmission route may be relevant to SARS-CoV-2. Aerosol and droplet transmission have been implicated in these areas and should not be ignored 
anywhere within the wastewater processing system. Concerns over design guidance for high-rise buildings requires attention and a whole-system approach for protocols and regulations for the entire wastewater system - from source (buildings) to post-processing effluent at the WWTP, would likely benefit public health.

\section{REFERENCES}

Corbishley A, Gally D, Fitzgerald S, Tidswell A and McAteer S (2020) Tracking SARS-CoV-2 via Municipal Wastewater. Centre of Expertise for Waters, Aberdeen, UK. See https://www.crew.ac.uk/ publication/tracking-sars-cov-2-municipal-wastewater (accessed 29/10/2020).

DHS (Department of Homeland Security) (2020) Master Question List for Covid-19 (caused by SARS-CoV-2). Department of Homeland Security, Washington, DC, USA. See https://www.dhs.gov/ publication/st-master-question-list-covid-19 (accessed 27/10/2020).

Ding S and Liang TJ (2020) Is SARS-CoV-2 also an enteric pathogen with potential fecal-oral transmission? A Covid-19 virological and clinical review. Gastroenterology 159(1): 53-61, https://doi.org/ 10.1053/j.gastro.2020.04.052.

Gormley M and Campbell DP (2006) The transport of discrete solids in above ground near horizontal drainage pipes: a wave speed dependent model. Building and Environment 41(4): 534-547, https://doi.org/10.1016/j.buildenv.2005.02.017.
Gormley M, Aspray TJ, Kelly DA and Rodriguez-Gil C (2017) Pathogen cross-transmission via building sanitary plumbing systems in a full scale pilot test-rig. PLoS ONE 12(2): e0171556, https://doi.org/ 10.1371/journal.pone.0171556.

Gormley M, Swaffield JA, Sleigh PA and Noakes CJ (2012) An assessment of, and response to, potential cross-contamination routes due to defective appliance water trap seals in building drainage systems. Building Services Engineering Research and Technology 33(2): 203-222, https://doi.org/10.1177/ 0143624411410619.

Gormley M, Templeton KE, Kelly DA and Hardie A (2014) Environmental conditions and the prevalence of norovirus in hospital building drainage system wastewater and airflows. Building Services Engineering Research and Technology 35(3): 244-253, https:// doi.org/10.1177/0143624413485080.

Jones DL, Baluga MQ, Graham DW et al. (2020) Shedding of SARS-CoV-2 in feces and urine and its potential role in person-to-person transmission and the environment-based spread of Covid-19. Science of The Total Environment 749: 141364, https://doi.org/10.1016/j.scitotenv.2020.141364.

Kang M, Wei J, Yuan J et al. (2020) Probable evidence of fecal aerosol transmission of SARS-CoV-2 in a high-rise building. Annals of Internal Medicine, https://doi.org/10.7326/ M20-0928.

WHO (World Health Organization) (2003) Consensus Document on the Epidemiology of Severe Acute Respiratory Syndrome (SARS). WHO, Geneva, Switzerland. See https://apps.who.int/iris/handle/ 10665/70863 (accessed 29/10/2020). 